\title{
A spatial analysis of referrals to a primary mental health programme in Western Sydney from 2012 to 2015
}

\author{
Cailin Maas, ${ }^{1}$ Jose A. Salinas-Perez, ${ }^{2,3}$ Nasser Bagheri, ${ }^{3}$ Sebastian Rosenberg, ${ }^{3}$ William Campos, ${ }^{4}$ \\ James A. Gillespie, ${ }^{5}$ Luis Salvador-Carulla ${ }^{3}$ \\ ${ }^{1}$ Brain and Mind Centre, University of Sydney, Camperdown NSW, Australia; ${ }^{2}$ Department of Quantitative \\ Methods, Universidad Loyola Andalucia, Dos Hermanas, Seville, Spain; ${ }^{3}$ Centre for Mental Health \\ Research, Research School of Population Health, Australian National University, Acton ACT, Australia; \\ ${ }^{4}$ WentWest, Western Sydney Primary Health Network, Blacktown NSW, Australia; ${ }^{5}$ Menzies Centre for \\ Health Policy and Sydney School of Public Health, Charles Perkins Centre, University of Sydney, NSW, \\ Australia
}

\begin{abstract}
Access to Allied Psychological Services is a primary mental health programme targeting hard-to-reach populations throughout Australia. This research aims to identify patterns of referrals to the programme in the Western Sydney Primary Health Network region from 2012 to 2015. The referral rates were analysed by using spatial autocorrelation indexes and spatial regression. The study area was described through the identification of the most disadvantaged areas and through consideration of three socio-eco-
\end{abstract}

Correspondence: Jose A. Salinas-Perez, Department of Quantitative Methods, Universidad Loyola Andalucia, Avda. de las Universidades s/n, 41704 Dos Hermanas, Seville, Spain.

Tel. +34.955.641.600 (ext. 494).

E-mail: jsalinas@uloyola.es

Key words: Primary mental health; Spatial clustering; Spatial modelling; Referrals; Australia.

Contributions: CM, JASP, JAG, LSC, conceptualisation; CM, WC, data curation; JASP, NB, CM, formal analysis; CM, JASP, NB, SR, WC, JAG, LSC, investigation; CM, JASP, writing; NB, SR, WC, JAG, LSC, reviewing.

Conflict of interest: the authors declare no potential conflict of interest.

Funding: this work was supported by Western Sydney Partners in Recovery Flexible Funding Program [contract number: 029351 0788] in the framework of the project titled Mapping of Mental Health Care Programs in the Western Sydney Local Health District, 2015.

Received for publication: 19 March 2019.

Revision received: 28 August 2019.

Accepted for publication: 12 September 2019.

${ }^{\circ}$ Copyright: the Author(s), 2019

Licensee PAGEPress, Italy

Geospatial Health 2019; 14:773

doi:10.4081/gh.2019.773

This article is distributed under the terms of the Creative Commons Attribution Noncommercial License (CC BY-NC 4.0) which permits any noncommercial use, distribution, and reproduction in any medium, provided the original author(s) and source are credited. nomic indicators: percentage of Aboriginal and Torres Strait Islander Australians, low educational attainment and low weekly incomes. A large hot spot (identifying high referral rates) was located across the duration of the study in the south-western urban area that partially covered a disadvantaged area. The main cold spot (identifying low referral rates) was located in the south-eastern urban area, covering another disadvantaged area, however critically this association disappeared over time. Our modelling showed that the referral rates had a direct association with the percentage of Aboriginal and Torres Strait Islander peoples with low incomes, and an indirect association with low educational attainment. The results and technique are useful in monitoring and addressing inequality in health planning and policy.

\section{Introduction}

In response to low treatment rates for common mental disorders a key change in mental health care over the past 15 years has been the willingness of the Australian Federal government to increase investment in primary mental health care (Bassilios et al., 2010 , 2013). Among others, this initiative manifested in two programmes: the Medicare-funded Better Access to Mental Health Care (Better Access) programme, and the Access to Allied Psychological Services (ATAPS) programme - from July 2016 called the Primary Mental Health Care services programme.

The ATAPS programme enables general practitioners to refer consumers to allied health professionals, mostly psychologists, for low-cost evidence-based mental health care (Bassilios et al., 2010). ATAPS was a very small, capped programme, offered at no or low cost to consumers and designed to specifically target people with a diagnosed mental disorder (Tier 1 initiative) and high needs groups in the community (Tier 2 initiative) namely: people from low socio-economic areas or other at-risk groups in the community such as women with perinatal depression, individuals at risk of suicide or homeless, children at risk of developing a psychological disorder, or Aboriginal and Torres Strait Islander peoples (Bassilios et al., 2016). Thus, the ATAPS programme is an important model for affordable primary mental health service delivery which deserves further study.

The ATAPS programme has been evaluated in a range of reports and scientific articles (Morley et al., 2007; Australian Government Department of Health, 2010; Bassilios et al., 2013, 2016; Hyde, 2014; King et al., 2015). However, these evaluations 
did not analyse critical parts of the programme, specifically how well ATAPS resources were allocated to areas of most need and how this changed over time. This question can be addressed through spatial analysis, which is considered a useful tool to study the relationship between space, time and healthcare access (Koschinsky, 2013).

Previous research using spatial analysis on mental health data is limited in Australia. Spatial smoothing techniques were used to study psychological distress rates in Sydney (Mayne et al., 2018), and national suicide mortality rates across Australia (Cheung et al., 2012). Spatial clustering techniques were used to identify hot spots and cold spots of dementia risk in west Adelaide (Bagheri et al., 2018), and on the suicide mortality rates in Queensland (Qi et al., 2010). Related to this study, the activity rates of Better Access, the other Australian primary mental health care programme, were studied geographically and temporally in South Australia (Carson et al., 2016), but without spatial analysis.

The aim of this research is to identify and describe patterns of referrals to the ATAPS programme in the Western Sydney Primary Health Network (PHN) region (Australia) from 2012 to 2015 using spatial clustering and regression methods to assess and monitor changes met and unmet need.

\section{Materials and Methods}

\section{Study area and spatial units}

This study explores the referral rates of people residing in Australia by referrers located within the Western Sydney PHN region to ATAPS providers for the financial years 2012-13, 201314 and 2014-15. The Western Sydney PHN region has a population of 947 thousand inhabitants (2016) and is located in the Greater Sydney area of New South Wales. The region is comprised of five Local Government Areas (LGAs), local administrative divisions, defined in 2011 (reduced to four in 2016). LGAs include two welldefined geographical areas: the urban and populated areas in the south (Auburn, Blacktown, Holroyd and Parramatta LGAs), and the semi-rural and lowly populated state and national park area in the north (The Hills Shire LGA).

The smallest spatial unit available for the geographical identification of referrals to ATAPS providers was the postal area (POA) level. However, there is a low geographical correspondence between LGA and POA boundaries. As such, the regional boundaries of the Western Sydney PHN either completely or partially encompass 44 POAs, which are the units of the present study.

\section{Access to Allied Psychological Services referrals datasets and sociodemographic data}

This analysis used a subset of referral records provided by WentWest, the public primary healthcare provider organisation in the region. The total number of referrals made between 2012 and 2015 was 7,023 that was reduced due to incomplete or erroneous data. As such, a total of 5,365 referrals were the scope for this study. Consumer gender and age provided information to calculate the direct standard rates of referrals per 1,000 population.

The POAs were described by using three sociodemographic indicators describing hard-to-reach populations, as defined by the ATAPS programme (Bassilios et al., 2016): i) low weekly incomes: percentage of people aged 14 and over with weekly income below $\$ 400$; ii) low educational attainment: percentage of people aged 14 and over that did not attend school or with an educational level below school year 8; iii) Aboriginal and Torres Strait Islander peoples as a percentage of the total population.

Population and sociodemographic data for POAs was obtained from the Australian Bureau of Statistics Census 2011 and 2016. As there was no exact census population for the study periods, the populations were approximated using the census 2011 to calculate the indicators in the period 2012-13, the mean between the census 2011 and 2016 population for the indicators in 2013-14, and the census 2016 population for the indicators in 2014-15.

Additionally, the Index of Relative Socio-economic Advantage and Disadvantage of 2011 and 2016 calculated by the Australian Bureau of Statistics (Radisich and Wise, 2012) was used to depict the Australian 20\% most disadvantaged POAs as a choropleth layer in the maps.

\section{Spatial data analysis}

This study used the Moran's I and the Getis-Ord's Gi global indexes to detect spatial clustering in the geographical distribution of the ATAPS referral rates (Getis, 2007). Later the local Moran's $I$ and Getis-Ord's $G i^{*}$ (Anselin, 2010) were conducted to locate statistically significant groups of POAs in close proximity with each other with high values (hot spots) and low values (cold spots) of referral rates.

Spatial relationships between rates of ATAPS referrals and the three sociodemographic indicators selected were assessed by using spatial regression models. Spatial models are recommended as a suitable alternative to Ordinary Least Squares (OLS) models when the regression residuals are spatially correlated in order to correct this misspecification and to improve the model controlling for the spatial dependence (Anselin and Bera, 1998). Moran's I and Langrage Multipliers (LM) tests are usually used to assess if the model is biased by spatial dependence. Spatially correlated residuals can indicate that the dependent variable is affected by the values of the dependent variable in nearby places (spatial lag), that the errors are correlated in nearby places (spatial error), or both these situations simultaneously (Anselin, 1988).

The relationship among spatial units for the analyses was considered through a spatial weight matrix, which defined the associations between pairs of units considering the polygon continuity of first order (directly neighbouring POAs). The analysis was performed using a Geographic Information System and spatial analysis software (ArcGIS 10C and GeoDa 1.8.16.4).

\section{Results}

\section{Spatial clustering analysis}

The direct standardised rates of ATAPS referrals by consumer POA in the three periods are shown in Figure 1. The spatial distribution of the consumer referral rates is not random according to the global autocorrelation indexes in any of the three periods $(2012-2013: I=0.566, \mathrm{P} \leq 0.000, G=0.239$, $\mathrm{P} \leq 0.000 ; 2013-2014: I=0.362, \mathrm{P} \leq 0.000 ; G=0.171, \mathrm{P} \leq 0.000$; 2013-2014: $I=0.262, \mathrm{P} \leq 0.001 ; G=0.160, \mathrm{P} \leq 0.000)$.

The results of the local $I$ and $G i^{*}$ for ATAPS referral rate by consumer POA are presented in Figures 2 and 3, respectively. Across the whole study period, both methods identified a 
statistically significant hot spot of high referral rates to the south-west of Western Sydney (Blacktown LGA), although this appeared to diminish becoming smaller and less significant over time. There was a partial coincidence between this hot spot and more disadvantaged POAs in the south-west of the region across time.

In contrast to the relative stability of the hot spot, the cold spots changed over time. One of the cold spots was identified in the north of the rural area of The Hills Shire LGA by Moran's $I$ analysis in 2014/2015, and Getis-Ord's $G i *$ analysis in $2013 / 14$ and $2014 / 2015$. A second cold spot was found by the Getis-Ord's $G i^{*}$ analysis in the south-east (Auburn and Parramatta LGAs) in 2012/13 and 2013/2014. Critically, this cold spot overlapped the disadvantaged POAs located in the south-east of the region in the first period, was neighbouring in the second, and finally disappeared in the third period.
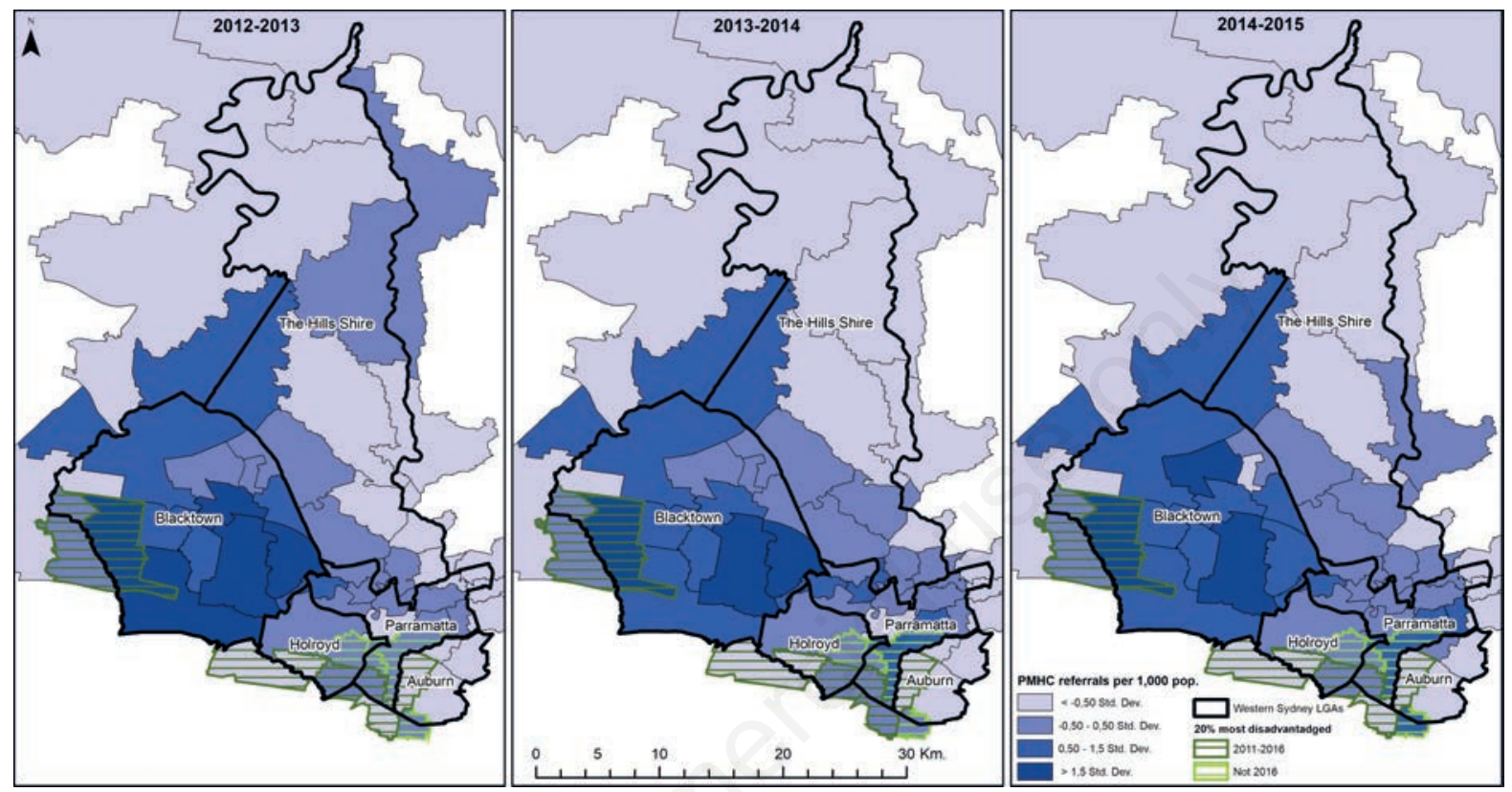

Figure 1. Access to Allied Psychological Services referral rates by consumer postcode in Western Sydney Primary Health Network region (2012-2015). PMHC, Primary Mental Health Care services; LGA, Local Government Area.
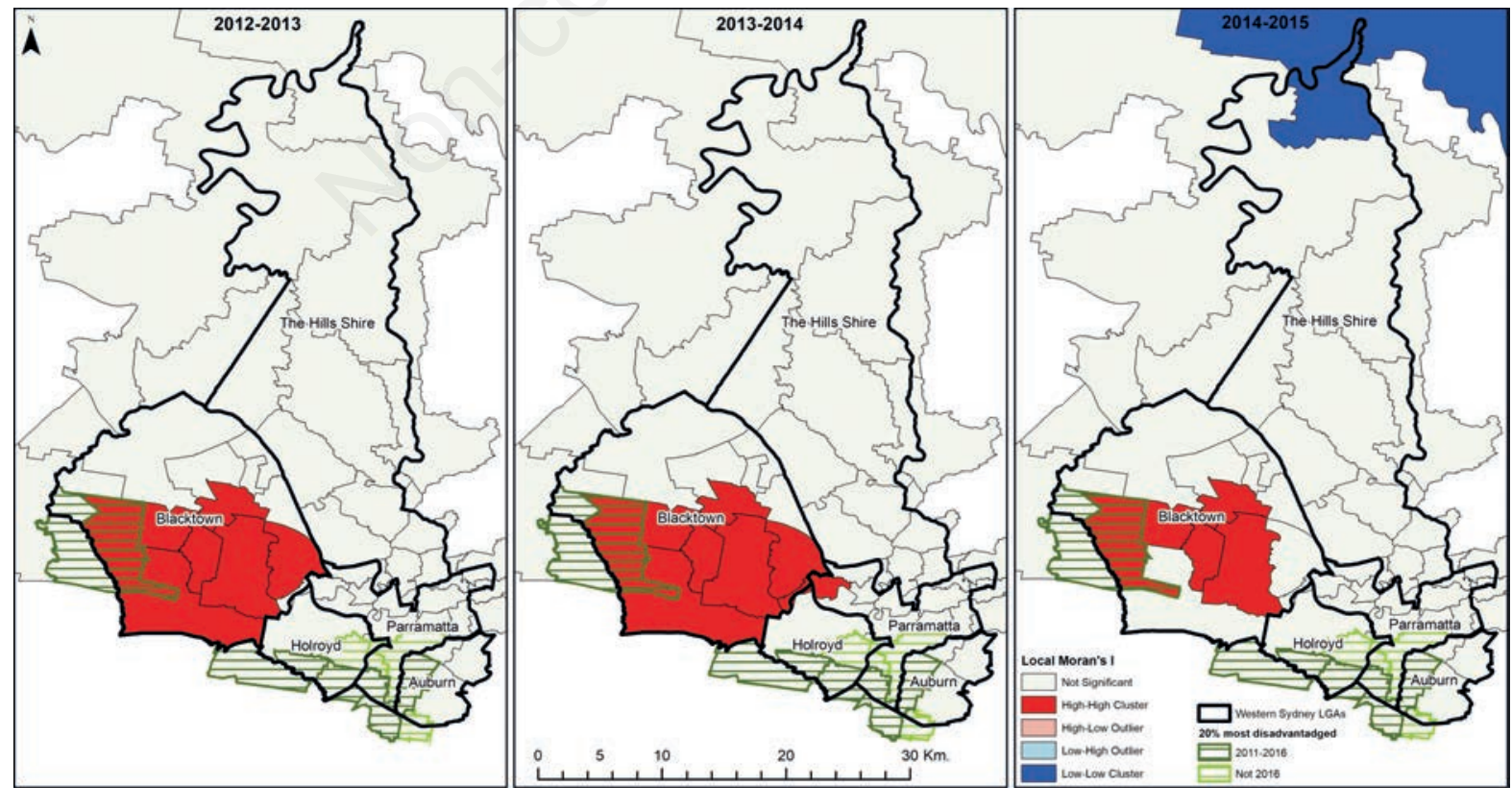

Figure 2. Local Moran's I Cluster and Outlier Analysis of the Allied Psychological Services referral rates by consumer postcode in Western Sydney Primary Health Network region (2012-2015). LGA, Local Government Area. 


\section{Spatial regression models}

The results of the OLS regression model built with the three sociodemographic indicators for the study period are shown in Table 1. The models did not show collinearity and the error was only not normally distributed in the first model.
According to the diagnostic tests, the models presented spatial autocorrelation in their residuals so they could be improved using spatial regressions. The Robust LM tests indicated (the scores were significant) that the Spatial Lag model was the proper alternative for the first model, while the Spatial Error model was suitable for the other two models.
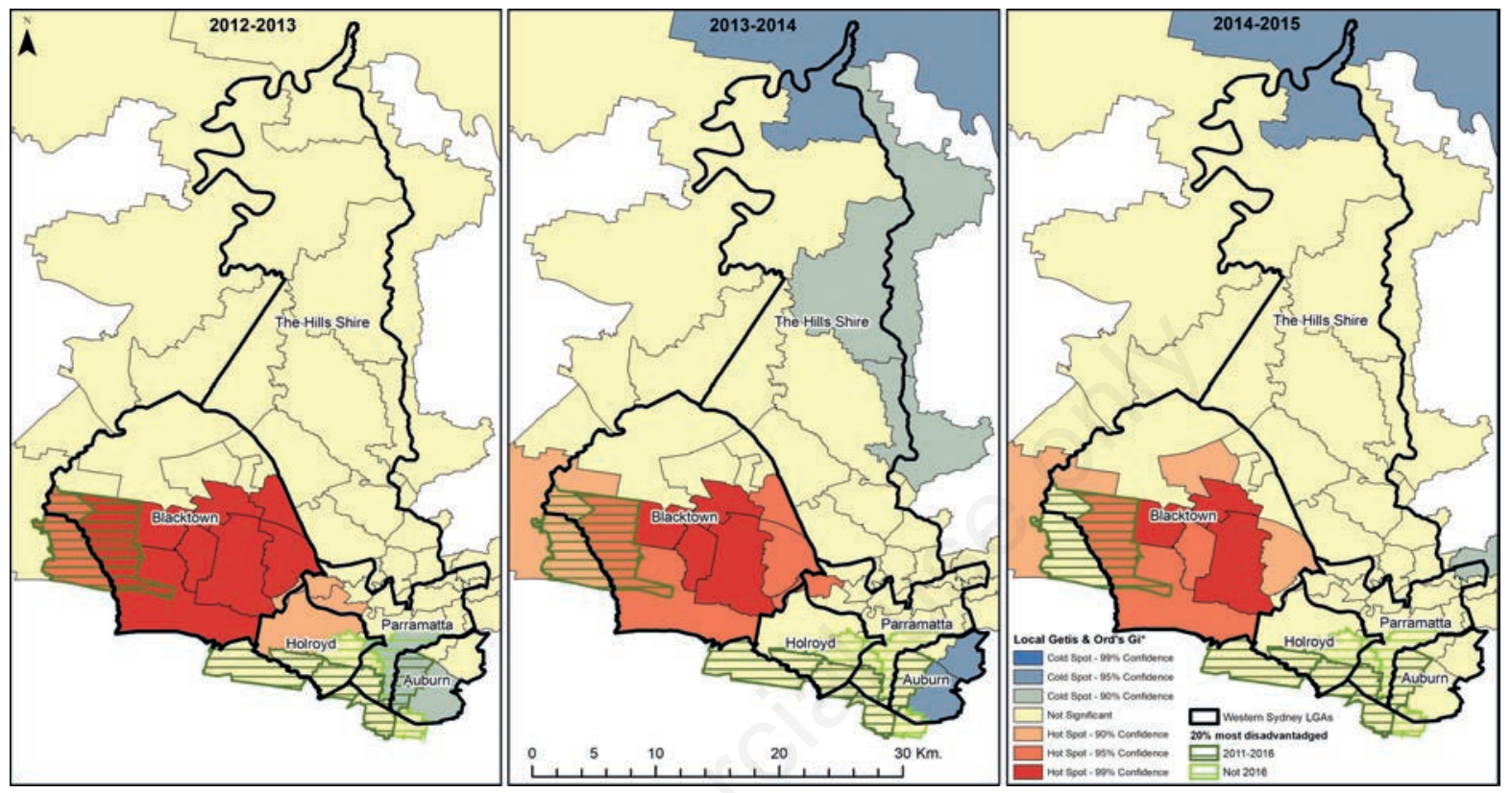

Figure 3. Getis-Ord's Gi* Hot Spot analysis of the Analysis of the Allied Psychological Services referral rates by consumer postcode in Western Sydney Primary Health Network region (2012-2015). LGA, Local Government Area.

Table 1. Ordinary Least Squares models for Access to Allied Psychological Services referral rates in Western Sydney Primary Health Network region from 2012 to 2015.

\section{2-13} 2013-14 2014-15

Regression model

Constant

\% Low education

$\%$ Low income

\% Aboriginal and Torres Strait Islander peoples

Regression diagnosis

$\mathrm{R}^{2}$

F-statistic

Akaike info criterion

Diagnosis for multicollinearity

Condition number

Diagnosis Normality of Errors Jarque-Bera test

Diagnosis for heteroscedasticity Breusch-Pagan test

Diagnosis for spatial dependence

Moran's I (error)

LM (lag)

Robust LM (lag)

Lagrange Multiplier (error)

Robust LM (error)

LM, Langrage Multiplier. ${ }^{*} \mathrm{P}<0.1 ;{ }^{*} \mathrm{P}<0.05 ; * * * \mathrm{P}<0.01$.
$-1.198$

$-0.108 *$

$0.065^{*}$

$0.295^{* * *}$

0.179

$2.912^{* *}$

121.509

23.037

$-1.797$

$-0.099$

$-0.186^{*}$

$0.152^{* *}$

$0.397^{* * *}$

$0.113^{*}$

$0.387^{* * *}$

$32.611^{* * *}$

2.900

0.219

$3.729 * *$

144.343

0.200

$3.338^{* *}$

145.707

26.548

27.061

$5.076^{* * *}$
$20.333^{* * *}$
$3.885^{* *}$
$16.654^{* * *}$
0.206

0.206

1.552

1.901

2.867

1.596

$5.290 * * *$

$13.930 * * *$

0.171

$17.673^{* * *}$

$3.915^{* *}$

$3.642 * * *$
$5.004^{* *}$

0.434

$7.276^{* * *}$

$2.706^{*}$ 
Finally, the results of the Spatial Lag and Spatial Error regression models for the three periods are shown in Table 2 . The coefficients for each explanatory variable were significant at $<0.1$ at the least, some were lower at $<0.01$, except for percentage of people with low educational level in the last period. The $R^{2}$ was by 0.5 except for the last period when it dropped to 0.3 . The models did not present heteroscedasticity since the scores for the BreushPagan test were always non-significant. Now the spatial autocorrelation tests did not show spatial dependence in the residuals, and the performance of the spatial models were improved respect to the OLS models, so the Akaike info criterion decreased. The results for all the models indicated that the relationship between the rate of referrals and the rate of low educational attainment was inverse, while with the rates of low weekly incomes and Aboriginal and Torres Strait Islander peoples were direct.

\section{Discussion}

A critical part of effective mental health policy and planning is to better understand the impact mental health programmes have in the community. This study focuses on primary mental health referrals data in the Wester Sydney PHN region. To the best of our knowledge, this is the first time that the geographical patterns of ATAPS referrals has been analysed in an Australian health region. This study is embedded within the framework of the Atlas of Integrated Mental Health Care in Western Sydney that generated a systemic mental health map for this region, including the analysis of the social and demographic characteristics, health-related needs, service availability and care capacity (Salvador-Carulla et al., 2016; Fernandez et al., 2017). Spatial analysis of service utilisation is another element within the strategy of the local integrated mental health atlases to address the study of healthcare ecosystems. Healthcare ecosystems work as a hierarchy of interrelated systems and entities that cannot be understood in isolation (Forget and Lebel, 2001; Laihonen, 2012), such as social and natural environments, services, providers and regulations. Thus, the health ecosystem approach facilitates the study of health systems as a whole which allows for capturing their complexity, uncertainty, dynamism, non-linearity and multi-dimensionality (SalvadorCarulla et al., 2006). The knowledge provided by this type of study is useful for such information-based health policy-making in the local context (Lewin et al., 2009; Allen et al., 2014).

\section{Spatial clusters of Access to Allied Psychological Services referral rates}

The large hot spot revealed areas where the programme was likely in high demand. The hot spot covered many non-disadvantaged POAs as well as a low socioeconomic area. This indicates that the programme may be meeting the need of the low socioeconomic area. However, it also reflects earlier work by Meadows et al. (2015) which found greater use of publicly funded primary mental health services, in that case the Better Access programme, by people residing in the areas of the most advantage quintiles in Australia. According this study, it may show that socio-economic advantage is associated with easier access to specialist care, although it is necessary to note that ATAPS consumers usually come from more disadvantaged social stratum than Better Access consumers (Bassilios et al., 2016).

The cold spot in the north indicated low programme activity in rural areas in the two last periods. However, a previous study detected a higher utilisation of the ATAPS programme in rural areas (Morley et al., 2007), while Better Access, the alternative fee based primary programme, was used more in urban areas (Meadows et al., 2015; Carson et al., 2016). The proximity to urban areas may explain this different behaviour in Western Sydney PHN region. Conversely and crucially, the disappearance of the south-eastern cold spot which overlapped an area of higher disadvantage may show that the ATAPS programme reached more people over time in urban areas where there was a deficit of referrals and high need. This is particularly relevant as this is one of the few programmes that is not associated with co-payment in secondary care. The impact of out-of-pocket expenses on accessibility and equity has been extensively studied in health care (Sanwald and Theurl, 2015). Out-of-pocket costs disproportionately impact individuals with the greatest health needs including Aboriginal and Torres Strait Islander peoples, people with chronic illnesses and people living in rural and remote areas (Laba et al., 2015).

Table 2. Spatial Lag and Error models for Access to Allied Psychological Services referral rates in Western Sydney Primary Health Network region from 2012 to 2015.

\begin{tabular}{|c|c|c|c|}
\hline & 2012-13 & 2013-14 & 2014-15 \\
\hline \multicolumn{4}{|l|}{ Regression model } \\
\hline Spatial model & Spatial Lag & Spatial Error & Spatial Error \\
\hline Constant & $-1.327 *$ & $-3.957 * * *$ & -2.558 \\
\hline \% Low education & $-0.093^{* *}$ & $-0.225^{* *}$ & -0.088 \\
\hline$\%$ Low income & $0.056^{* *}$ & $0.188 * * *$ & $0.132 * *$ \\
\hline \% Aboriginal and Torres Strait Islander peoples & $0.136^{*}$ & $0.305^{* * *}$ & $0.373^{* * *}$ \\
\hline Spatial term & Wi: $0.624^{* * *}$ & Lambda: $0.671^{* * *}$ & Lambda: $0.482^{* * *}$ \\
\hline \multicolumn{4}{|l|}{ Regression diagnosis } \\
\hline$R^{2}$ & 0.491 & 0.519 & 0.347 \\
\hline Akaike info criterion & 107.076 & 128.443 & 139.281 \\
\hline \multicolumn{4}{|l|}{ Diagnosis for heteroscedasticity } \\
\hline Breusch-Pagan test & 2.217 & 1.742 & 3.073 \\
\hline \multicolumn{4}{|l|}{ Diagnosis for spatial dependence } \\
\hline Likelihood Ratio Test & $16.433^{* * *}$ & $15.900 * * *$ & $6.426^{* *}$ \\
\hline Moran's I (residuals) & -0.043 & -0.003 & -0.006 \\
\hline
\end{tabular}

$* \mathrm{P}<0.1 ; * * \mathrm{P}<0.05 ; * * * \mathrm{P}<0.01$ 
The cold spot in the south-east was associated with the other low-economic area. A lower referral to services in the most disadvantaged areas was also detected for the other primary health programme (Better Access) across Australia (Meadows et al., 2015). This lower referral rate in more disadvantaged areas may indicate reduced opportunities to access an effective treatment, therefore, health inequity. These would best be addressed through social policies specifically designed to increase access to psychological treatment in disadvantaged areas, and the knowledge and use of this programme by primary carers in these areas (Enticott et al., 2016).

\section{Indicators associated with Access to Allied Psychological Services referral rates}

The spatial models designed in this study concluded that higher referral rates were associated with localised geographical areas with higher rates of Aboriginal and Torres Strait Islander peoples and people with low weekly incomes, and smaller rates of lower educational levels. These socio-economic characteristics were more pronounced in the two most disadvantaged areas in the region.

Firstly, it is worth mentioning that the percentage of Aboriginal and Torres Strait Islander peoples seem to have an interaction effect on the expected relationship between low incomes and low educational attainment in the models for the three periods. Thus, while the correlations between the two later variables were positive independently, when they were introduced in the models with the former variable this relationship became the opposite. Although not in the scope of this paper, this interaction effect would deserve further research.

Poorer and more disadvantaged populations are more prone to mental disorders (Allen et al., 2014). An Australian study found that the prevalence of high/very high psychological distress (K10 scale) in the first quintile of disadvantage in 2012 at $16.1 \%$ was the greatest of all the quintiles, this represented more than double the rate of distress than the most advantaged quantile (6.9\%) (Enticott et al., 2016). Furthermore, the relationship between mental health and low incomes is well-known. Lower levels of income have been shown to predict higher levels of psychological distress (Enticott et al., 2016).

Adult Aboriginal and Torres Strait Islander peoples were three times more likely than non-Indigenous adults to have very high psychological distress (Cunningham and Paradies, 2012), and their suicide rates were twice that of the non-Indigenous population (De Leo et al., 2011). There are significant barriers to Aboriginal and Torres Strait Islander peoples accessing mental health services (Isaacs et al., 2010; Sveticic et al., 2012). Their influence on high referral rates may be direct, indicating ATAPS made gains towards the target of facilitating their access to mental health services. However, the relationship may be indirect due to the association between Aboriginal and Torres Strait Islander peoples and socioeconomic disadvantage (Jorm et al., 2012). This requires further investigation which would benefit from a strength-based health promotion approach rather than a problem centred approach (Brough et al., 2004; McPhail-Bell et al., 2015).

Conversely, higher educational levels have been stated as a protective factor of psychological distress in Australia (Enticott et al., 2016). However, and like our findings, educational attainment showed the opposite effect in low-income urban communities in Montreal (Canada) (Caron et al., 2007; Caron and Liu, 2010). This could be due to unfulfilled high expectations for a better quality of life by better educated populations suffering economic disadvantage. The findings show that according to the regression models, lower educational level was not a decisive factor in programme demand, quite the opposite.

\section{Limitations}

There are several limitations in this study. First, the study unit was the POA level due to the data availability and confidentiality. A lower level of aggregation would have added more detail to the study. Second, the study analysed only three key indicators of psychological distress. Future analysis should include additional factors related to spatial clustering in mental health including more socio-economic variables, service provision, and service accessibility measures (Salinas-Pérez et al., 2015; Rodero-Cosano et al., 2016). Third, this research is affected by several common limitations in geographical studies that must be taken into account, such as the ecological fallacy and the boundary problem.

\section{Conclusions}

Using spatial data analysis, this research has shown that the geographical distribution of the referrals to a primary mental health programme in the Western Sydney PHN was not random but patterned. The areas with high referral rates remained stable across time and should be investigated further and be the subject of specific attention from health planning and policy. Critically, the disappearance of the main cold spot may indicate an improvement in access to the ATAPS programme in a disadvantaged area, reaching populations at risk that had a deficit of referrals in the two first periods. This paper has demonstrated the potency of spatial analysis to analyse and monitor patterns in the development of primary mental health programmes. The increased use of this type of analysis is critical to ensure the right services are reaching the right people in the right places.

\section{References}

Allen J, Balfour R, Bell R, Marmot M, 2014. Social determinants of mental health. Int Rev Psychiatry 26:392-407.

Anselin L, 1988. Spatial econometrics: methods and models. Kluwer, Dordrecht, The Netherlands.

Anselin L, 2010. Local Indicators of Spatial Association-LISA. Geogr Anal 27:93-115.

Anselin L, Bera AK, 1998. Spatial dependence in linear regression models with an introduction to spatial econometrics. In: Ullah A, Giles DE, eds. Handbook of applied economic statistics. Marcel Dekker, New York, NY, pp 237-289.

Australian Government Department of Health, 2010. Outcomes and proposed next steps: review of the Access to Allied Psychological Services Component of the Better Outcomes in Mental Health Care Program February 2010. Australian Government Department of Health, Canberra, Australia.

Bagheri N, Wangdi K, Cherbuin N, Anstey KJ, 2018. General practice clinical data help identify dementia hotspots: a novel geospatial analysis approach. J Alzheimers Dis 61:125-34.

Bassilios B, Nicholas A, Reifels L, Machlin A, Ftanou M, King K, Fletcher J, Blashki G, Burgess P, Pirkis J, 2013. Evaluating the Access to Allied Psychological Services (ATAPS) component 
of the Better Outcomes in Mental Health Care (BOiMHC) program: Ten year consolidated ATAPS evaluation report. Centre for Health Policy, Programs and Economics, University of Melbourne, Melbourne, Australia.

Bassilios B, Nicholas A, Reifels L, King K, Fletcher J, Machlin A, Ftanou M, Blashki G, Burgess P, Pirkis J, 2016. Achievements of the Australian access to allied psychological services (ATAPS) program: summarising (almost) a decade of key evaluation data. Int J Ment Health Syst 10:61.

Bassilios B, Pirkis J, Fletcher J, Burgess P, Gurrin L, Kink K, Kohn F, Blashki G, 2010. The complementarity of two major Australian primary mental health care initiatives. Aust N Z J Psychiatry 44:997-1004.

Brough M, Bond C, Hunt J, 2004. Strong in the City: towards a strength-based approach in Indigenous health promotion. Health Promot J Aust 15:215-20.

Caron J, Latimer É, Tousignant M, 2007. Predictors of psychological distress in low-income populations of Montreal. Can J Public Health 98:S35-44.

Caron J, Liu A, 2010. A descriptive study of the prevalence of psychological distress and mental disorders in the Canadian population: comparison between low-income and non-low-income populations. Chronic Dis Can 30:84-94.

Carson D, Bidargaddi N, Schrader G, Allison S, Jones GM, Bastiampillai T, Strobel J, 2016. Geography of primary mental health care through the Better Access initiative in South Australia 2006-2010. Aust J Rural Health 24:188-92.

Cheung YTD, Spittal MJ, Yip PSF, Pirkis J, 2012. Spatial analysis of suicide mortality in Australia: Investigation of metropolitanrural-remote differentials of suicide risk across states/territories. Soc Sci Med 75:1460-8.

Cunningham J, Paradies YC, 2012. Socio-demographic factors and psychological distress in Indigenous and non-Indigenous Australian adults aged 18-64 years: analysis of national survey data. BMC Public Health 12:95.

De Leo D, Sveticic J, Milner A, 2011. Suicide in Indigenous people in Queensland, Australia: trends and methods, 1994-2007. Aust N Z J Psychiatry 45:532-8.

Enticott JC, Meadows GN, Shawyer F, Inder B, Patten S, 2016. Mental disorders and distress: associations with demographics, remoteness and socioeconomic deprivation of area of residence across Australia. Aust N Z J Psychiatry 50:1169-79.

Fernandez A, Gillespie JA, Smith-Merry J, Feng X, Astell-Burt T, Maas C, Salvador-Carulla L, 2017. Integrated mental health atlas of the Western Sydney Local Health District: gaps and recommendations. Aust Health Rev 41:38-44.

Forget G, Lebel J, 2001. An ecosystem approach to human health. Int J Occup Environ Health 7:S3-38.

Getis A, 2007. Reflections on spatial autocorrelation. Reg Sci Urban Econ 37:491-6.

Hyde J, 2014. Lessons from Australia in the public funding of mental health services. Can Psychol Can 55:139-43.

Isaacs AN, Pyett P, Oakley-Browne MA, Gruis H, Waples-Crowe $P, 2010$. Barriers and facilitators to the utilization of adult mental health services by Australia's Indigenous people: seeking a way forward. Int J Ment Health Nurs 19:75-82.

Jorm AF, Bourchier SJ, Cvetkovski S, Stewart G, 2012. Mental health of Indigenous Australians: a review of findings from community surveys. Med J Aust 196:118-21.

King K, Bassilios B, Nicholas A, Fletcher J, Reifels L, Pirkis J,
2015. Assessing patient satisfaction in an Australian primary mental health care context. Adv Ment Health 12:161-6.

Koschinsky J, 2013. The case for spatial analysis in evaluation to reduce health inequities. Eval Program Plann 36:172-6.

Laba TL, Usherwood T, Leeder S, Yusuf F, Gillespie J, Perkovic V, Wilson A, Jan S, Essue B, 2015. Co-payments for health care: what is their real cost? Aust Health Rev 39:33-6.

Laihonen H, 2012. Knowledge structures of a health ecosystem. J Health Organ Manag 26:542-58.

Lewin S, Oxman AD, Lavis JN, Fretheim A, Garcia Marti S, Munabi-Babigumira S, 2009. SUPPORT tools for evidenceinformed policymaking in health 11: finding and using evidence about local conditions. Health Res Policy Syst 7:S11.

Mayne DJ, Morgan GG, Jalaludin BB, Bauman AE, 2018. Does walkability contribute to geographic variation in psychosocial distress? A spatial analysis of 91,142 members of the 45 and up study in Sydney, Australia. Int J Environ Res Public Health 15:275.

McPhail-Bell K, Bond C, Brough M, Fredericks B, 2015. 'We don't tell people what to do': ethical practice and Indigenous health promotion. Health Promot J Aust 26:195-9.

Meadows GN, Enticott JC, Inder B, Russell GM, Gurr R, 2015. Better access to mental health care and the failure of the Medicare principle of universality. Med J Aust 202:190-4.

Morley B, Pirkis J, Naccarella L, Kohn F, Blashki G, Burgess P, 2007. Improving access to and outcomes from mental health care in rural Australia. Aust J Rural Health 15:304-12.

Qi X, Tong S, Hu W, 2010. Spatial distribution of suicide in Queensland, Australia. BMC Psychiatry 10:106.

Radisich P, Wise P, 2012. Socio-economic indexes for areas: robustness, diversity within larger areas and the new geography standard. Australian Bureau of Statistics, Canberra, Australia.

Rodero-Cosano ML, Salinas-Pérez JA, González-Caballero JL, García-Alonso CR, Lagares-Franco C, Salvador-Carulla L, 2016. A multi-level analysis of the relationship between spatial clusters of outpatient-treated depression, risk factors and mental health service planning in Catalonia (Spain). J Affect Disord 201:42-9.

Salinas-Pérez JA, Rodero-Cosano ML, García-Alonso CR, Salvador-Carulla L, 2015. Applying an evolutionary algorithm for the analysis of mental disorders in macro-urban areas: the case of Barcelona. Spat Econ Anal 10:270-88.

Salvador-Carulla L, Fernandez A, Maas C, Smith-Merry J, Gillespie J, Astell-Burt T, Feng X, 2016. The integrated mental health atlas of Western Sydney. Western Sydney Partners in Recovery, Mental Health Policy Unit, Brain and Main Research Institute, Faculty of Health Sciences, University of Sydney, Sydney, Australia.

Salvador-Carulla L, Haro JM, Ayuso-Mateos JL, 2006. A framework for evidence-based mental health care and policy. Acta Psychiatr Scand 111:5-11.

Sanwald A, Theurl E, 2015. Out-of-pocket payments in the Austrian healthcare system - a distributional analysis. Int J Equity Health 14:94-7.

Sveticic J, Milner A, De Leo D, 2012. Contacts with mental health services before suicide: a comparison of Indigenous with nonIndigenous Australians. Gen Hosp Psychiatry 34:185-91. 